\title{
ACTITUDES HACIA LA INMIGRACIÓN Y LOS INMIGRANTES: ¿EN QUÉ ES ESPAÑA EXCEPCIONAL?
}

\section{ATTITUDES TOWARDS IMMIGRATION AND IMMIGRANTS: WHAT ABOUT SPAIN'S EXCEPTIONALISM?}

SebAstiAn RINKEn*

Resumen: Cuando una sociedad inmigratoria experimenta graves problemas económicos, actitudes hostiles hacia la población inmigrada suelen incrementarse: en este sentido apuntan teorías ampliamente reconocidas, así como una nutrida evidencia empírica. No obstante, pese a reunir las aludidas condiciones, el caso español desmiente estas previsiones: durante los primeros seis años de la crisis económica iniciada en 2008, la preocupación por el tema inmigratorio y la animosidad hacia las personas inmigradas han disminuido. ¿En qué radica esta excepcionalidad española? Este artículo retrata la situación de partida y la evolución de las actitudes desde 2008, identifica varias hipótesis explicativas, y señala sus implicaciones para las políticas públicas.

Palabras clave: actitudes hacia la inmigración y los inmigrantes, crisis económica, teoría de competencia grupal, teoría de posición grupal.

* Doctor en Ciencias Políticas y Sociales por el Instituto Universitario Europeo. Científico Titular, Instituto de Estudios Sociales Avanzados (IESA-CSIC). 


\begin{abstract}
When an immigration society is struck by economic hardship, hostility towards immigrants is prone to rise: this prediction is borne out both by widely accepted theories and abundant empirical evidence. However, despite matching the conditions of large immigrant presence and strong economic woes, the Spanish case does not fit that forecast. Throughout the first six years of the economic crisis that began in 2008, stated concern for immigration has decreased, as did manifest hostility toward immigrants. How can such Spanish exceptionality be explained? This article traces the situation at baseline, as well as the evolution of attitudes since 2008, to then identify various explanatory hypotheses and discern their implications for public policy.
\end{abstract}

Keywords: attitudes towards immigration and immigrants, economic crisis, group competition theory, group position theory.

\title{
1. INTRODUCCIÓN
}

En muchos países europeos, durante estos últimos años han surgido, o se han fortalecido, corrientes de opinión marcadamente hostiles en materia inmigratoria; corrientes que en no pocos casos, están siendo fomentadas e instrumentalizadas por partidos nacionalistas o incluso (como en Grecia), abiertamente fascistas. Tal deterioro de la opinión pública es consistente con la teoría de competencia (o conflicto) grupal: según este ampliamente aceptado paradigma conceptual, un contexto económico desfavorable sería proclive a provocar animosidad creciente hacia personas de procedencia foránea, rechazo que tendería a ceñirse en determinados grupos de origen. Según estas premisas, la reciente historia de España reúne los requisitos para un claro empeoramiento de las actitudes hacia los inmigrantes. Como es sabido, la combinación entre un mercado laboral expansivo y unas políticas migratorias comparativamente abiertas había convertido a España en un país con tasas muy altas de inmigración neta. En 2008, este auge encontró un brusco fin. La crisis económica afectó de lleno a lo que, según el juicio concurrente de gobernantes y ciudadanía, había sido el principal beneficio de la inmigración: la aportación de mano de obra a una economía boyante.

Sin embargo, lejos de originar una ola de rechazo, la crisis parece haber tenido un impacto escaso, o hasta benévolo, sobre la opinión 
pública española en materia inmigratoria: la mención de este tema en cuanto problema social ha ido decreciendo desde 2007, quedando reducida a niveles bajísimos ${ }^{1}$. Remotos quedan los tiempos en los que, en el barómetro del Centro de Investigaciones Sociológicas (CIS) y otras encuestas, amplias partes de la población señalaban la inmigración como preocupación destacada. Sin descartar que en años venideros pudiese surgir una renovada inquietud, queda el hecho incontrovertible de que durante varios años de profunda crisis económica y social, la ciudadanía española ha estado mostrando un asombroso sosiego al respecto, teniendo en cuenta los aludidos antecedentes comparativos y conceptuales. Ello es más llamativo si cabe, dado que en estos últimos años, los roces fronterizos en Ceuta y Melilla, así como la presión migratoria en aguas del Mediterráneo, han atraído un considerable interés mediático.

En este texto, daré un paso hacia la explicación de esta sorprendente ecuanimidad. En primer lugar, recapitularé el estado de la opinión pública con anterioridad a la crisis. En segundo lugar, recordaré supuestos y predicciones de la teoría de competencia grupal. Tercero, esbozaré la evolución de las opiniones y actitudes en materia inmigratoria durante el período 2008-2013. Posteriormente, identificaré cuatro posibles explicaciones de la configuración observada, para desarrollar, paso seguido, la hipótesis más novedosa. Finalmente, trazaré las implicaciones de todo ello.

\section{RECAPITULACIÓN}

Para conocer las posturas de la ciudadanía española hacia la inmigración y los inmigrantes, disponemos de fuentes muy diversas en cuanto a enfoque territorial y diseño metodológico. En este breve recordatorio de la situación con anterioridad a la crisis, solo mencionaré estudios cuantitativos cuya ejecución repetida permite abordar también la evolución reciente; así, más adelante podremos retomar estos hilos.

Pese a contener apenas información específica, el antes aludido barómetro del CIS es probablemente la fuente más conocida sobre opiniones en materia migratoria, dada su elevada periodicidad y

1 Ver http://www.cis.es/cis/opencm/ES/11_barometros/index.jsp 
aparente facilidad de interpretación. Como recordaba, en el período 2008-2013, la notoriedad de la inmigración como problema social ha disminuido de modo progresivo; con valores cercanos al $60 \%$, su máximo se había alcanzado en 2006, durante la denominada «crisis de los cayucos». La preocupación manifiesta por la inmigración alcanzó picos menos pronunciados en 2001, 2002, y 2005, coincidentes con debates sobre la regulación normativa y un posible efecto llamada (Méndez Lago, 2007). Del contraste entre fases de alta y baja notoriedad podemos deducir, en una primerísima aproximación, que la ciudadanía tiende a reaccionar con inquietud a la percepción de que el control fronterizo carece de eficacia, y que esa percepción está modulada por procesos de politización y mediatización.

Con periodicidad anual, el CIS realiza también una encuesta monotemática por encargo del Observatorio del Racismo y la Xenofobia. Los correspondientes informes equiparan las actitudes hacia la inmigración con actitudes ante la diversidad étnica y racial (por ejemplo, Cea D’Ancona y Vallés Martínez, 2009); equiparación que conlleva la consideración como moralmente reprochable de cualquier postura desfavorable ante la inmigración y sus efectos. Para eludir dicha conflación conceptual, conviene analizar los datos tal y cómo los proporciona el CIS en su espacio digital ${ }^{2}$. Resulta que en época de bonanza, una mayoría de la población autóctona apoyaba la llegada de trabajadores inmigrantes, siempre y cuando se produjera de manera ordenada y para ejercer empleos poco cualificados. El Eurobarómetro y la Encuesta Social Europea (véase el resumen en OPAM, 2011: 102-117) amparan la conclusión de que a principios del siglo XXI, los españoles valoraron el hecho inmigratorio de modo comparativamente favorable, sobre todo respecto a su dimensión laboral. Sin embargo, no podemos obviar una salvedad importante: la contribución de los inmigrantes al desarrollo económico fue reconocida, y avalada, fundamentalmente con vistas al desempeño de ocupaciones de baja deseabilidad social (Abad Márquez, 2002; Cachón Rodríguez, 2006).

En un contexto en el que el mercado laboral se expandía a un ritmo frenético, las políticas de regularización de los inmigrantes y su integración en los principales servicios públicos contaban también

2 Ver http://datosbd.cis.es/ciswebconsultas/estudioSearchLoad.htm; buscando por «población - inmigración» se accede a los estudios 2731, 2773, 2817, 2846, 2918 y 2967 , realizados entre 2007 y 2012. 
con amplio respaldo. No obstante, incluso en plena bonanza económica, una mayoría opinaba que los inmigrantes estarían recibiendo un nivel elevado de protección por parte del Estado, en comparación con otros colectivos (estudio CIS 2731, P1); asimismo, dos de cada tres españoles consideraban "excesivo» el número de inmigrantes. Esta última valoración puede atribuirse en parte a la novedad del hecho inmigratorio y la velocidad de su evolución, y en parte, a una mala imagen de determinados grupos de procedencia en cuanto a su adaptación a reglas esenciales de convivencia; imagen que a su vez, es difícil de distinguir de una disposición denigratoria hacia estos colectivos. Como focos de problemas percibidos, destacaban la inseguridad ciudadana por un lado, y el ejercicio de la religión musulmana, por otro. En el ápice del boom, la mitad de la población española manifestaba desconfianza hacia la población inmigrante en su conjunto y/o determinados grupos de procedencia (estudio CIS 2731, P12 y P13).

Existen datos pormenorizados para algunas CC.AA.; al referirse a regiones con estructuras económicas bien distintas, es ilustrativo comparar los estudios elaborados por los Observatorios de la Inmigración andaluz y vasco, respectivamente ${ }^{3}$. En época expansiva, amplias mayorías en ambas CC.AA. apoyaban la incorporación de los inmigrantes al mercado laboral y a las políticas públicas del bienestar; y en ambas regiones, se articulaban recelos de varia índole, fruto parcialmente de estereotipos desfavorables y parcialmente, de la idea de que la responsabilidad para una integración exitosa recaería sobre todo en los propios alóctonos. Combinando datos cuantitativos y cualitativos, el estudio andaluz evidencia con particular claridad que la buena disposición de los autóctonos hacia las personas inmigradas presupuso, como contrapartida, la adaptación de estas a las principales reglas de convivencia. Esta noción de un «trato implícito» no constituye necesariamente un asimilacionalismo arcaico y forzoso; más bien evoca la metáfora de huésped y hogareño, en toda su ambivalencia.

Al basarse en abanicos bastante amplios de indicadores, y bajo el supuesto de que las posturas ante varias facetas del hecho

3 Ver http://www.juntadeandalucia.es/justiciaeinterior/opam/?q=estudio_OPIA y http://www.ikuspegi-inmigracion.net/es/; la situación con anterioridad a la crisis queda retratada por Rinken y Pérez Yruela (2007) e Ikuspegi (2008), disponibles en los referidos espacios digitales. 
inmigratorio reflejan una actitud subyacente, las tipologías de actitudes permiten sintetizar la configuración de la opinión pública. En España, la propuesta más conocida distingue entre actitudes tolerantes, ambivalentes, y reacias - grados de una receptividad que se estaría refiriendo indistintamente a la inmigración y a la diversidad étnica y racial. Según esta concepción, en el tramo final de la época expansiva (año 2007) los reacios tenían, en el conjunto del país, una ligera preeminencia (37\%) sobre ambivalentes (34\%) y tolerantes (29\%) (Cea D’Ancona y Vallés Martínez, 2009). Con una metodología parecida, en el País Vasco se observaban proporciones mayores de ambivalentes y tolerantes, y claramente menores, de reacios (Ikuspegi@k, 2012: 101). El estudio realizado en Andalucía (Rinken y Pérez Yruela, 2007) combina hallazgos cualitativos y cuantitativos para calibrar la difusión social de distintas maneras de razonar acerca de la inmigración. Con anterioridad a la crisis predominaban las actitudes funcionalista y desconfiada, con cerca del 30\% cada una; ambas radican en apreciaciones de (des-)ventajas, aunque con resultados opuestos. Por su parte, las actitudes más decididas en sentido favorable (solidario) y desfavorable (excluyente), respectivamente, eran minoritarias.

\section{PREDICCIÓN}

Ante este trasfondo, no resulta descabellado temer que una severa crisis del mercado laboral pudiese ocasionar un rechazo creciente de la población inmigrante, enfocado en su caso en determinados grupos de procedencia. Al principio del ciclo expansivo, los responsables de la política migratoria española divisaron claramente este riesgo (Cornelius, 1995), pero pudieron perderlo de vista posteriormente, en un contexto caracterizado por un exceso generalizado de confianza (Rinken, 2013).

En la literatura científica, el mecanismo causal que pudiera originar tal deterioro de las actitudes fue descrito décadas atrás. En un magnífico libro, Allport (1954: 227-233) sugirió que los prejuicios contra grupos alóctonos aumentarían si a la presencia visible de población inmigrante, se sumasen dificultades económicas. Planteada inicialmente como parte de un compendio de factores, esta propuesta teórica obtuvo un eco extraordinario, sobre todo después de que Quillian (1995) recuperase su enfoque en el contexto demográfico y 
económico, más allá de la vulnerabilidad ocupacional a escala individual. La amplia aceptación por generaciones posteriores de investigadores convirtió a esta concepción de las relaciones intergrupales en hegemónica (Ceobanu y Escandell, 2010), bajo denominaciones como teoría de competencia grupal y teoría de amenaza grupal; a lo largo de los años, se ha ido acumulando una nutrida evidencia empírica a su favor.

Estos antecedentes inducen a presagiar que la crisis española pudiese provocar un deterioro de las relaciones entre personas autóctonas e inmigrantes. Un aviso especialmente preocupante es proporcionado por el caso griego: en el país heleno, la animosidad hacia inmigrantes degeneró en violencia racista. Sin obviar diferencias previas en cuanto a predisposiciones hacia alóctonos, tampoco cabe olvidar que España comparte con Grecia la condición de frontera Sur de Europa, siendo por tanto sujeta a una presión inmigratoria estructural; ni que otros países europeos con culturas democráticas bien asentadas (Francia y Gran Bretaña, entre otros), están también viéndose afectados por un auge del populismo anti-inmigrante. En línea con lo dicho, el deterioro de las actitudes debería ser especialmente pronunciado en Andalucía, al ser una región fronteriza con elevadísimas tasas de paro.

\section{TRAYECTORIAS DISPARES}

Según comenté antes, la notoriedad decreciente de la inmigración como problema social sugiere que en España, en el período 2008-2013 no se cumplieron las predicciones de la teoría de competencia grupal. Desde una óptica comparativa, es llamativo que solo uno de cada 30 españoles menciona la inmigración como problema social destacado, cuando dicha proporción alcanza el $18 \%$ en el conjunto de la EU y supera un tercio de la población alemana, británica, o danesa ${ }^{4}$. En Andalucía, las menciones de este tema se

4 Véase el Eurobarómetro 82 (http://ec.europa.eu/public_opinion/archives/ eb/eb82/eb82_first_en.pdf), de noviembre 2014 (concretamente, QA3); la Encuesta Social Europea (www.upf.edu/ess/datos) y la encuesta «Transatlantic Trends» (www.fbbva.es) también ofrecen datos comparativos sobre las actitudes ante la inmigración y su evolución. 
redujeron incluso más (al 1\% en 2013) que en el conjunto nacional y sobre todo, en el País Vasco (al 11,6\% en 2012), con sus cifras relativamente asumibles de paro. Tanto en comparación internacional como interregional, parecería por tanto que estamos ante una situación paradójica: a mayor nivel de desempleo, menor preocupación por la inmigración. Con objeto de contrastar y en su caso, matizar este diagnóstico preliminar, trazaré la trayectoria de otros indicadores sobre distintas facetas del hecho inmigratorio; los agruparé según su tónica predominante fuese el deterioro, la estabilidad, o una mejoría.

\section{DETERIORO}

Ya a principios de 2008 surgieron indicios de que el cambio de ciclo afectaría a la apreciación de la mano de obra inmigrante. En dinámicas grupales realizadas en Andalucía, la utilidad económica dejó de constituir un discurso autosuficiente, pasando a englobarse en razonamientos de índole solidaria, desconfiada, o excluyente, según el caso (Rinken et al., 2009: 173-204). Por aquellas fechas, la cosmovisión funcionalista se mantenía aparentemente intacta en encuestas estructuradas (Rinken y Velasco Dujo, 2010); sin embargo, al profundizarse la crisis, el ideario utilitarista dio muestras de agotamiento también en estas (Rinken et al., 2013). En 2013, el 49\% de los encuestados divisaron "pocos o ningún» efecto positivo de la inmigración para Andalucía; en 2008, solo el 23\% habían respondido así. De ser el primer efecto positivo, el mercado laboral pasó a encabezar las menciones de efectos negativos; al sopesarse aspectos positivos y negativos de la inmigración, las valoraciones desfavorables aumentaron en 27 puntos entre 2008 y 2013. Además, retrocedieron las actitudes solidaria y funcionalista, mientras creció la difusión de actitudes recelosas. De forma menos pronunciada, tendencias parecidas se observan a escala nacional (cf. estudio CIS 2967; ver nota 2): aumenta la mención del mercado laboral como efecto negativo de la inmigración, aumenta el acuerdo con afirmaciones que sugieren competencia laboral, y disminuye la percepción de que los inmigrantes desempeñan trabajos que los españoles no quieren.

Las opiniones se vuelven más restrictivas también respecto a la regulación de los flujos inmigratorios: la expulsión de inmigrantes irregulares duplica apoyos, y se hace mayor hincapié en la legalidad 
como criterio de admisión. Una lenta erosión se detecta respecto a la calidad percibida de determinados servicios públicos, sobre todo en el País Vasco; esta región destaca, asimismo, por un repunte de ideas estereotipadas, como es la noción de que las prácticas religiosas de los inmigrantes amenazarían "nuestro estilo de vida» (Ikuspegi@k, 2012: 51). En época de crecimiento económico, amplias mayorías solían expresarse a favor de la participación social y política de los inmigrantes; la mayor reducción (unos 20 puntos en Andalucía y unos 10, en España) de un respaldo antaño abrumador se da respecto a la reagrupación familiar, cuestión relacionada intrínsecamente con la regulación de flujos.

\section{ESTABILIDAD}

Por lo demás, las opiniones sobre el acceso de la población inmigrante a derechos sociales y políticos se mantienen esencialmente estables; en muchos casos, ello supone la continuidad de un apoyo extenso, con altibajos que evidencian cierto endurecimiento de las posturas durante 2008-2011, seguido por una recuperación de posiciones más abiertas, a partir de 2012. El acceso al sistema sanitario genera más dudas que la universalidad de otros servicios públicos (Rinken et al., 2013: 29-35).

A escala nacional, la valoración general de la inmigración se deteriora relativamente poco: en 2012, un 40\% manifiesta una visión positiva, proporción no muy diferente de la observada en 2008 (el 46\%) e igual a la de 2010 y 2011 (estudio CIS 2967, P23). La difusión social de la intolerancia apenas cambia (Cea D’Ancona y Vallés Martínez, 2014: 308): retrocediendo del 40\% alcanzado en 2011, los reacios recobran en 2012 la cuota del 37\% que ya mantenían de 2007 a 2010; por su parte, los tolerantes bajan del 29\% (2007) al 26\% (2012), mientras los ambivalentes aumentan. También en el País Vasco, tolerantes (39\%), ambivalentes (41\%) y reacios (21\%) recuperan en 2012 proporciones similares a las observadas hasta 2010, quedando el deterioro en 2011 como un interludio (Ikuspegi@k, 2012: 103). La continuidad de las etiquetas semánticas oculta vaivenes de las posturas subyacentes: en 2011 y 2012, los ambivalentes se vuelven a posicionar próximos a los tolerantes, contrarrestando una tendencia opuesta durante los primeros años de crisis (Cea D'Ancona y Vallés Martínez, 2014: 309-312). 
Estabilidad, con altibajos menores en algún año u otro, se observa también respecto a los prejuicios hacia los llamados exogrupos, por lo menos según los datos para Andalucía y el conjunto de España. Aproximadamente la mitad de la población manifiesta estereotipos negativos; así ocurre, por ejemplo, al valorar el grado de simpatía que inspiran determinados colectivos de procedencia (CIS 2967, P27) o al expresar menor confianza hacia grupos específicos (Rinken et al., 2013: 40). Aunque no sea de naturaleza científica, hemos de considerar otro dato más, de importancia transcendental: según las estadísticas administrativas del Ministerio del Interior, la incidencia de agresiones racistas o xenófobas sigue siendo baja (MIR, 2014). La información disponible sugiere que las relaciones entre personas de distinta procedencia no se han deteriorado, por lo menos no de forma alarmante.

\section{MEJORÍA}

Un tercer grupo de indicadores ha evolucionado en sentido favorable en el transcurso de la crisis. A su vez, estos se subdividen según dicha mejoría se manifieste (a) desde el inicio de la crisis, (b) después de mantenerse inicialmente estable, o (c) invirtiendo una tendencia desfavorable. Señalaré ejemplos destacados para cada tipo de trayectoria.

(a) Aparte de la notoriedad como problema social, una postura cada vez menos recelosa se desprende de la proporción decreciente (7 puntos menos, según el CIS) de quienes perciben como «excesivo» el número de inmigrantes residentes; un descenso parecido se constata en Andalucía.

(b) De 2008 hasta 2011, se mantenía estable la proporción de españoles (un 42\%) que valoran como «demasiado tolerantes» las leyes en materia inmigratoria; en 2012, esta proporción bajó en siete puntos (estudio CIS 2967, P9).

(c) Hasta 2011, iba consolidándose la idea de que los inmigrantes estarían recibiendo «mucha» o «bastante» protección por parte del Estado; en 2012, tales apreciaciones bajaron de golpe en 15 puntos porcentuales (estudio CIS 2967, P1). Un cambio similar se observa en Andalucía (Rinken et al., 2013: 15); asimismo, entre 2011 y 2013 disminuyó la proporción de andaluces que expresan 
antipatía contra los inmigrantes (Rinken et al., 2013: 46). En el País Vasco, la percepción de que «los inmigrantes se benefician excesivamente del sistema de protección social» decrece desde 2010 (Ikuspegi@k, 2012: 52); y en los tres territorios considerados, disminuye la preocupación por la relación entre inmigración e inseguridad ciudadana. Varios indicadores más trazan una $\mathrm{U}$ invertida durante estos años de crisis.

En resumidas cuentas, la evolución de las opiniones y actitudes en materia inmigratoria fue llamativamente dispar, según qué aspecto consideremos. Durante el período 2008-2013, se produjo un marcado deterioro de las valoraciones respecto a la dimensión económica de la inmigración, sobre todo en Andalucía, región muy desfavorecida en cuanto al estado de su mercado laboral. Las posturas se volvieron más reacias también en materia de regulación de flujos y en cuanto a la visión global de la inmigración. Sin embargo, se ha mantenido un amplio respaldo, menos holgado que en época de bonanza pero sólido desde una perspectiva comparada, respecto de la participación social y política de los inmigrantes. Es más, según los datos disponibles, la difusión de estereotipos negativos hacia el colectivo inmigrante no habría aumentado; y las posturas en materia de convivencia entre personas alóctonas y autóctonas parecen haberse suavizado a partir de 2012, en contraste con cierto deterioro durante la fase inicial de la crisis. La discrepancia entre unas apreciaciones cada vez menos favorables en cuanto al impacto económico de la inmigración, por un lado, y la estabilidad o incluso mejoría de las relaciones inter-grupales, por otro, es especialmente evidente en Andalucía: el calamitoso nivel del desempleo no impide que aumente la simpatía declarada hacia la población inmigrante. En síntesis, se agudiza la antes referida paradoja: a mayor preocupación por el mercado laboral, menor hostilidad hacia las personas inmigrantes.

\section{HIPÓTESIS EXPLICATIVAS}

¿Cómo explicar esta desconexión entre el deterioro de las valoraciones económicas del hecho inmigratorio, por un lado, y la relativa serenidad de las actitudes hacia personas de procedencia foránea, por otro? Tal disimilitud de trayectorias no tiene necesariamente 
una causa única: más bien originará en una combinación de factores, de índole más o menos estable y de alcance social más o menos amplio. Dicho esto, seis años de crisis intensa son un período lo suficientemente largo como para implicar razones consistentes. Y para resultar convincente, la explicación de esta disociación debería ayudarnos a entender porqué la teoría de competencia grupal no es aplicable sin más, en esta ocasión.

Desde la comunidad científica apenas se han articulado propuestas al respecto. Extrapolando los argumentos, en gran parte implícitos, que se encuentran en la literatura, he podido desentrañar cuatro enfoques distintos.

(1) En primer lugar, se ha argumentado que la cultura política de la España post-franquista, con su matriz universalista en cuanto a derechos cívicos y sociales, supone la superación de recelos retrógrados, fomentando unas actitudes abiertas hacia la inmigración y los inmigrantes (Arango, 2013). Dicha matriz universalista comprende el debilitamiento de la distinción entre inmigración regular e irregular; debilitamiento que se plasma en el estatus del Padrón como «verdadera piedra angular del modelo español de gestión de la inmigración y de la integración de los inmigrantes» (Cebolla Boado y González Ferrer, 2013: 162). Esta configuración normativa es única en el mundo. Así, una excepcionalidad conllevaría otra: el sosiego ciudadano ante la inmigración radicaría en una legislación universalista en general, y aperturista en particular en cuanto al hecho inmigratorio se refiere. Nexo que, en versiones enfáticas de este enfoque, puede concebirse como aprendizaje social (Davidov y Meuleman, 2012; Schlueter, Meuleman y Davidov, 2013).

(2) En segundo lugar, cabría subrayar que una cosa son las actitudes en materia inmigratoria, y otra distinta, sus manifestaciones expresas. Si convirtiésemos el denominado sesgo de deseabilidad social (Phillips y Clancy, 1972) en paradigma interpretativo, deberíamos desconfiar de los datos disponibles sobre la evolución de las actitudes, sobre todo los generados por encuesta, ya que proporciones significativas de la población estarían ocultando sus posturas verdaderas. Esta interpretación conlleva la preocupante implicación de que tarde o temprano, la tensión entre opiniones reales y declaradas pudiera resultar excesiva. Cabría vaticinar por tanto el riesgo de un repentino vuelco de la opinión pública, alabado en su caso por políticos irresponsables; abundan los 
antecedentes comparativos en este sentido. Según este planteamiento, la excepcionalidad española residiría en la persistencia de las aludidas inhibiciones en un entorno de crisis, persistencia que a su vez, puede reconducirse al descrédito del nacionalismo centrípeto en época post-franquista (Arango, 2013). Estaríamos ante una variante pesimista de la hipótesis anterior; escepticismo que es nutrido por evidencia cualitativa acerca del deterioro de las actitudes en la fase inicial de la crisis (Rinken, 2011).

(3) Como tercera opción explicativa, cabría suponer un efecto retardador sobre la dinámica evolutiva de las actitudes en materia migratoria; es decir, la excepcionalidad española tendría caducidad (desconociéndose obviamente su fecha). Señalaba antes que la propia crisis ha estado acaparrando mucho protagonismo como preocupación ciudadana; pero junto a economía y paro, otras cuestiones más han obtenido notoriedad creciente, ¿por qué no la inmigración? Siguiendo una sugerencia de Kunovich (2004: 3941), es importante hacer hincapié en que la corrupción y la calidad de la clase política han sido, junto a la situación económica en sí, los principales problemas emergentes durante estos últimos años, y singularmente, desde 2011 (así lo evidencian el Barómetro del CIS y otras encuestas). Los reproches hacia las élites estarían colmando (de momento) el impulso por responsabilizar a otros de las estrecheces sufridas por amplias partes de la población española.

(4) Finalmente, cabe la posibilidad de que la relativa serenidad de las actitudes hacia el colectivo inmigrante se viese alimentada por la crisis, justamente en virtud de comparaciones intergrupales. Es decir, la propia percepción de la crisis y sus efectos estaría motivando actitudes relativamente relajadas hacia los alóctonos, de modo que la referida paradoja sería solo aparente y se convertiría en núcleo de la explicación del sosiego ciudadano en materia inmigratoria. De forma implícita, esta hipótesis surge cuando los bajos índices de animosidad son relacionados con la re-emigración de personas inmigradas, que estaría ocasionada a su vez por la precariedad ocupacional: «the devastating effects of the current economic crisis have motivated out-migration flows, and these, in turn, have de-problematized immigration» (ZamoraKapoor, 2013: 94). Tal y como es formulada aquí, esta propuesta explicativa es rudimentaria, al no examinarse su vinculación con las relaciones intergrupales, ni diferenciarse entre percepciones y hechos. A continuación, abordaré ambas cuestiones. 


\section{6. ÉXODO, COMPETENCIA GRUPAL, Y POSICIÓN RELATIVA: PUNTUALIZACIONES TEÓRICAS}

¿Por qué debería una fuerte corriente re-emigratoria redundar en una des-problematización del hecho inmigratorio? La literatura ofrece dos respuestas plausibles.

La primera de ellas se deriva directamente de los supuestos de la teoría de competencia grupal. Como recordaba antes, dicha teoría enfatiza percepciones de conflicto de interés, sobre todo de índole económica, como clave explicativa de tensiones intergrupales; la hostilidad hacia los inmigrantes tendería por tanto a aumentar en condiciones de alta visibilidad del colectivo alóctono, en combinación con una situación económica adversa. Respecto a ambos parámetros, cambios recientes pueden resultar tan o más importantes que niveles absolutos (Allport, 1954: 221). Ahora bien, las migraciones internacionales tienden generalmente a evolucionar al alza, de modo que no suelen darse escenarios empíricos en los que la población inmigrada disminuye con rapidez. Por tanto, puede considerarse novedoso vaticinar que un decrecimiento de la población inmigrante pudiese contribuir a aminorar la animosidad hacia este grupo social. El mecanismo causal sería el siguiente: la re-emigración masiva de población foránea ocasiona un decrecimiento palpable de la población activa; este conlleva una disminución de los conflictos de interés percibidos en materia laboral (y quizás en otros ámbitos), y por tanto, de la enemistad hacia colectivos alóctonos.

Una segunda aproximación tiene más profundidad sociológica, al referirse a la posición relativa de diversos colectivos sociales. Según su formulación clásica (Blumer, 1958), el rechazo del grupo subordinado (el alóctono en nuestro caso) por parte del grupo dominante radicaría en percepciones de amenaza a las prerrogativas de este. Muchos autores consideran que la teoría de posición grupal es esencialmente idéntica a la teoría de competencia grupal (cf. Quillian, 1995), prediciendo hostilidad creciente en contextos económicamente adversos. Kunovich (2004) recupera un matiz decisivo, notando que según Blumer (1958), el grupo dominante no se preocupa por el grupo subordinado en sí, sino por su propia posición frente a él. Por tanto,

With worsening economic conditions, immigrants may fall further behind native workers, which could decrease the threat 
posed by immigrants and, thus, reduce negative attitudes toward them (Kunovich, 2004: 39-40).

Así, la evolución de las actitudes hacia el colectivo inmigrante no dependería sin más de la coyuntura económica, ni tampoco del nivel de desempleo, sino del impacto percibido de la crisis sobre unos y otros. Mientras prevalezca la percepción de que los inmigrantes están afectados de manera especialmente dura, las actitudes hacia ellos se mantendrían estables, o incluso mejorarían. Una ola re-emigratoria puede considerarse la mejor prueba posible de que los inmigrantes están efectivamente siendo perjudicados con particular crudeza por la crisis. Desde esta perspectiva, asociándose el empeoramiento económico a un retroceso acusado de los inmigrantes, resulta comprensible que al profundizarse la crisis, las actitudes hacia las personas inmigradas evolucionasen favorablemente (véanse las referidas trayectorias en forma de U inversa). En resumidas cuentas, la excepcionalidad española residiría en la extensa aceptación de la idea de que, debido a su marcada precariedad ocupacional y social, amplias partes del colectivo foráneo estarían obligadas a la re-emigración.

\section{EL ÉXODO DE LA POBLACIÓN INMIGRADA: IMAGEN Y REALIDAD}

Una cosa es la imagen del éxodo, y otra distinta, la realidad demográfica. En cuanto a imagen, varios indicios apuntan a que en la ciudadanía española pudo asentarse cada vez más la expectativa de un éxodo multitudinario por parte de la población inmigrada:

- Como recordaba, durante el período expansivo se había generalizado una concepción instrumental de la mano de obra inmigrante, al estilo de «que se vengan... mientras hagan falta». El corolario lógico de esta noción es la idea de que cuando dejen de hacer falta, muchos inmigrantes se irán.

- En 2008, esta faceta de la cosmovisión utilitarista fue activada expresamente por el Gobierno español; el escaso éxito operativo del «Plan de Retorno» no le resta eficacia para vertebrar las orientaciones de la ciudadanía. A continuación, desde 2009 hasta 2011, el Gobierno dio escasísima publicidad a sus gestiones en 
materia migratoria, pese a la gran relevancia de algunas de ellas (LOEX; Reglamento); tal discreción contribuiría a que se asentara la referida expectativa.

- A partir de 2010, las estadísticas sobre flujos y stocks de extranjeros han venido constatando el fin del auge inmigratorio; desde 2012, prevalecen los movimientos emigratorios sobre los inmigratorios. Sin embargo, los números no avalan, ni mucho menos, la idea de que una mayoría de los inmigrantes estarían re-emigrando. Llama la atención que al publicar los datos, el INE solía obviar salvedades que hubieran matizado la imagen del éxodo, alimentando así una cobertura mediática en la que predominaba esta. Valga como ejemplo la nota de prensa relativa a los datos provisionales del Padrón a 1 enero de 2013ㄹ: se destaca la reducción de los extranjeros empadronados, sin mencionarse el impacto de las nacionalizaciones por residencia sobre este dato. Si bien es cierto que las notas de prensa no constituyen informes analíticos, también lo es que contribuyen a vertebrar las percepciones de la ciudadanía. De modo parecido, el Padrón provisional de 2014 se presentó sin señalar que sus datos estaban afectados por una comprobación periódica de si los extranjeros de procedencia comunitaria siguen residiendo en España, dando así lugar a la impresión (errónea) de que la disminución en unos 545.000 extranjeros pudo producirse en $2013^{6}$.

- Asimismo, es llamativo cómo se procedió a actualizar la estadística de extranjeros residentes; estadística cuya publicación había quedado suspendida durante un año, debido a que las naturalizaciones no causaban baja automática en el registro de tarjetas de residencia en vigor. Así, muchos de los inmigrantes que accedieron a la nacionalidad española en estos últimos años, seguían constando también como extranjeros con autorización de residencia vigente. Al publicarse los primeros datos depurados, se anuncia como descenso lo que en realidad, fue un aumento de los extranjeros residentes en España, en el trienio

5 Nota de Prensa 776, publicada el 22 de abril de 2013 (http://www.ine.es/ prensa/np776.pdf).

6 Nota de Prensa 838, publicada el 22 de abril de 2014 (http://www. ine.es/prensa/np838.pdf); véase el comentario de Amparo González Ferrer (http://www.eldiario.es/piedrasdepapel/revuelo-padron-exodo-extranjeros-ricos_6_252734752.html). 
2011-20137. Este curioso «fallo» semántico refuerza la impresión (cf. Rinken, 2013) de que la estadística pública forma parte integrante de la política gubernamental de comunicación en materia migratoria - en beneficio, por lo menos a corto plazo, de la cohesión social.

- La quinta ola del estudio OPIA permite calibrar hasta qué punto se ha generalizado la expectativa de éxodo: a mediados de 2013, más del $80 \%$ de los andaluces afirmaron su acuerdo con la idea de que «cuando no hay crecimiento económico, una mayoría de inmigrantes se va».

Por su parte, la realidad demográfica depende de las decisiones que millones de familias hayan tomado, o tomarán, a partir de una amplia gama de variables, muchas de ellas impredecibles. Según los datos disponibles, entre tarjetas y certificados vigentes y stock de nacionalizados, la población inmigrada estaría actualmente sumando unas seis millones de personas. Una parte de ellas podrían haber optado por emigrar, o hacerlo en años venideros; pero también es concebible que tarde o temprano, la ciudadanía española llegue a sorprenderse ante el volumen de población inmigrante firmemente asentada, y con autorización legal perfectamente válida.

\section{CONCLUSIONES}

En el período 2008-2013, la preocupación por el hecho inmigratorio y la animosidad hacia las personas inmigradas evolucionaron a la baja, pese a un contexto económico que a priori, haría presagiar un aumento de la aversión. Partiendo de esta constatación, he identificado cuatro posibles explicaciones de un sosiego ciudadano sorprendente, tanto desde una óptica conceptual, como bajo un prisma comparativo. Dichas hipótesis hacen hincapié, respectivamente, en la cultura política de la España post-franquista con su empeño por universalizar los derechos cívicos y sociales; en la inhibición que dicha cultura política supone respecto a la manifestación de prejuicios degradantes; en la desconfianza hacia las élites políticas y su

7 Nota de Prensa del MEYSS, publicada el 6 de agosto de 2014 (http://prensa.empleo.gob.es/WebPrensa/noticias/inmigracionemigracion/detalle/2289). 
gestión de la crisis, deflactándose así el posible aumento de animosidad hacia poblaciones alóctonas; y en la percepción de que la crisis afectaría a los inmigrantes con tal crudeza, que muchos de ellos se estarían viendo obligados a re-emigrar.

Esta última hipótesis guarda relación intrínseca con la teoría de competencia grupal, proposición conceptual que aparentemente, se ve cuestionada por el asombroso sosiego de la ciudadanía española en materia inmigratoria, en estos tiempos de crisis. Un auge re-emigratorio conllevaría una disminución de la población activa, reduciendo la sobresaturación del mercado laboral con demandantes de empleo y el riesgo de que pudiera percibirse competencia grupal al respecto. Es más, un éxodo masivo resultaría reconfortante para la población autóctona también con vistas a su posición relativa como grupo social, ya que se trataría de re-emigraciones obligadas, provocadas por una precarización ulterior de unas situaciones ocupacionales vulnerables ya en época de bonanza. Por tanto, la posición social de la población inmigrante estaría evolucionando marcadamente a la baja, aliviando así la preocupación de los autóctonos por posibles amenazas a su posición relativa. Ahora bien, es necesario distinguir las expectativas, o imágenes, por un lado, de la realidad demográfica, administrativa, y ocupacional, por otro. Según la hipótesis formulada aquí, resulta plausible que a corto plazo, la imagen del éxodo estaría contribuyendo a unas actitudes sosegadas hacia las personas inmigradas; pero no por ello debemos ignorar los riesgos que pudiesen surgir a medio plazo si la población española llegara a concluir que dichas expectativas no se cumplieron. Aunque duela constatarlo, cabe la posibilidad de que la excepcionalidad española reside en buena medida en una imagen acusadamente precaria y subalterna del colectivo alóctono; imagen que está muy alejada de la igualdad en el acceso a derechos y oportunidades que cabría suponer a raíz de la hipótesis universalista.

Las explicaciones discernidas aquí no son incompatibles: existen varias constelaciones plausibles. De combinarse las primeras tres hipótesis, al universalismo constituyente se unirían una difusa desaprobación de la intolerancia y una mala imagen de la clase política. Alternativamente, las hipótesis segunda, tercera y cuarta podrían convertirse en piezas complementarias de una conceptualización comprensiva: a la idea de que los inmigrantes se encuentran especialmente perjudicados por la crisis, y que esta fue provocada y/o agravada por la avaricia e incompetencia de los gobernantes, 
se juntaría inhibición a la hora de manifestar recelos. Incluso cabría compaginar los cuatro planteamientos, de modo que sobre el trasfondo de una cultura política universalista se desplegarían los restantes mecanismos explicativos, aunque con ciertas contradicciones y grados dispares de vigencia en distintas franjas de la población. Investigaciones futuras tendrán que dilucidar cuáles de las referidas hipótesis son avaladas por evidencia empírica, y en qué medida; tal comprobación se antoja especialmente difícil respecto a la segunda hipótesis, debido a escollos metodológicos bastante obvios.

Sin menoscabo de la posible, o hasta probable, complementariedad empírica de varías de las cuatro hipótesis identificadas, conviene señalar que sus implicaciones prácticas son bien distintas, y potencialmente antitéticas. Con vistas a preservar la cohesión social y la calidad de la convivencia a medio plazo, la primera hipótesis sugiere que el universalismo del modelo social español ha de fortalecerse. En cambio, la hipótesis del rechazo velado sugiere un énfasis en la pedagogía política, por un lado, y en la desactivación proactiva de los focos de tensión emergentes, por otro. La hipótesis del chivo expiatorio aconseja eludir en lo posible los debates públicos del hecho inmigratorio, mientras la hipótesis de la posición relativa implica la conveniencia de apuntalar la percepción ciudadana de una población inmigrante vulnerable y propensa a re-emigrar.

Algunas de estas explicaciones comparten el supuesto de que el riesgo de un repliegue hostil, en clave nativista o nacionalista, remitirá cuando se estabilice la situación macroeconómica. Por otra parte, nótese que de las cuatro hipótesis discernidas, tres conllevan un pronóstico reservado en cuanto a la evolución futura de las actitudes y por lo tanto, una enmienda a la idea de que la excepcionalidad española es necesariamente de índole duradera.

\section{AGRADECIMIENTOS}

Quisiera expresar mi gratitud a los evaluadores anónimos por sus críticas constructivas; y a la Dirección General de Coordinación de Políticas Migratorias de la Junta de Andalucía por confiar la realización del estudio OPIA al IESA-CSIC, durante el período considerado en este artículo. 


\section{REFERENCIAS}

Abad Márouez, L. (2002): «Trabajadores inmigrantes en las economías avanzadas. La paradoja de la demanda adicional en mercados con exceso de oferta», en F. García Castaño y C. Muriel López, III Congreso sobre la Inmigración en España, Vol. II: 459-67. Granada, Universidad de Granada.

Allport, G.W. (1954): The Nature of Prejudice. Reading: Addison-Wesley.

Arango, J. (2013): Exceptional in Europe? Spain's Experience with Immigration and Integration. Washington, D.C.: Migration Policy Institute (http:// www.migrationpolicy.org/research/exceptional-europe-spains-experience-immigration-and-integration).

Blumer, H. (1958): «Race prejudice as a sense of group position». Pacific Sociological Review 1 (1): 3-7.

Cachón Rodríguez, L. (2006): "Los inmigrantes en el mercado de trabajo en España (1996-2004)», en E. AJA y J. ArANGo, Veinte años de inmigración en España. Perspectivas jurídica y sociológica, 175-201. Barcelona, CIDOB.

Cea D’Ancona, Ma.Á. y Vallés Martínez M. (2014): Evolución del racismo, la xenofobia y otras formas conexas de intolerancia en España. Informe 2013. Madrid: OBERAXE, Ministerio de Empleo y Seguridad Social (http://explotacion.mtin.gob.es/oberaxe/documentacion_descargaFicher o?bibliotecaDatoId=4056).

- (2009): Evolución del racismo y la xenofobia en España. Informe 2009. Madrid: OBERAXE, Ministerio de Trabajo e Inmigración (http://explotacion.mtin.gob.es/oberaxe/documentacion_descargaFichero?biblioteca DatoId=150).

Cebolla Boado, H. y González Ferrer, A. (eds.) (2013): Inmigración: ¿integración sin modelo? Madrid, Alianza.

Ceobanu, A.M. y Escandell, X. (2010): «Comparative analyses of public attitudes toward immigrants and immigration using multinational survey data: A review of theories and research». Annual Review of Sociology 36: 309-28.

Cornelius, W.A. (1995): «Spain: the uneasy transition from labor exporter to labor importer», en W.A. Cornelius, P.L. Martin y J.F. Hollifield, Controlling Immigration: A Global Perspective, 331-69. Stanford, CA, Stanford U.P.

Davidov, E. y Meuleman, B. (2012): «Explaining attitudes towards immigration policies in European countries: The role of human values». Journal of Ethnic and Migration Studies 38 (5): 757-75. 
IKusPegi (2008): Barómetro 2007. Percepciones y actitudes hacia la inmigración extranjera. Bilbao: Observatorio Vasco de Inmigración (http://www. ikuspegi-inmigracion.net/documentos/investigacion/es/bar_2007_completo.pdf).

IKUSPEGI@K (2012): Barómetro 2012. Percepciones y actitudes hacia la población extranjera. Bilbao: Observatorio Vasco de Inmigración (http://www. ikuspegi-inmigracion.net/documentos/barometros/2012/bar_2012_cas_ ok.pdf)

Kunovich, R.M. (2004): «Social structural position and prejudice: an exploration of cross-national differences in regression slopes». Social Science Research 33 (1): 20-44.

Méndez Lago, M. (2007): «Actitudes ante la inmigración. Una mirada desde las encuestas», en E. AJA y J. Arango, La inmigración en España en 2006. Anuario de inmigración y de políticas de inmigración en España (edición 2007), 68-81. Barcelona, CIDOB.

OPAM (2011): Informe Anual «Andalucía e Inmigración 2010». Observatorio Permanente Andaluz de las Migraciones, Consejería de Empleo, Junta de Andalucía (http://www.juntadeandalucia.es/empleo/OPAM/sites/default/ files/DOC/Informe\%20Anual\%202010.pdf).

MIR (2014): Informe sobre la evolución de los delitos de odio en España durante el año 2013. Ministerio del Interior, Madrid (http://www.interior. gob.es/web/interior/prensa/balances-e-informes/2013).

Phillips, D.L. y Clancy, K.J. (1972): «Some effects of «Social Desirability» in survey studies». American Journal of Sociology 77 (5): 921-40.

Quillian, L. (1995): «Prejudice as a response to perceived group threat: population composition and anti-immigrant and racial prejudice in Europe». American Sociological Review 60: 586-611.

Rinken, S. (2011): «La evolución de las actitudes ante la inmigración en tiempos de crisis económica: un análisis cualitativo», en E. AJA, J. ARANGO Y J. Oliver (eds.), Inmigración y crisis económica. Impactos actuales y perspectivas de futuro. Anuario de la inmigración en España, edición 2010, 24-47. Barcelona, CIDOB.

- (2013): «El día después: la sociología de las migraciones en tiempos de crisis». Revista Española de Sociología, no 19: 171-86 (http://www.fesweb.org/res/sumarios/019.php).

Rinken, S., Escobar Villegas, Ma .S., Cerrillo, J.A. y Espinosa de los MonTEROS, E. (2013): Opiniones y actitudes de la población andaluza ante la inmigración, 5a Edición (OPIA-V). Sevilla: Observatorio Permanente Andaluz de las Migraciones, Consejería de Justicia e Interior, Junta de 
Andalucía (http://www.juntadeandalucia.es/justiciaeinterior/opam/sites/ default/files/DOC/Informe_estudio_OPIA-V.pdf).

Rinken, S. y Pérez Yruela, M. (2007): Opiniones y actitudes de la población andaluza ante la inmigración. Sevilla: Consejería de Gobernación, Junta de Andalucía (http://www.juntadeandalucia.es/justiciaeinterior/opam/sites/default/files/DOC/texto_completo_OPIA_I.pdf).

Rinken, S., Silva Perejón, M., Velasco Dujo, S. y Escobar Villegas, M ${ }^{\text {a }}$.S. (2009): Opiniones y actitudes de la población andaluza ante la inmigración (II): entre la estabilidad y el cambio. Sevilla: Consejería de Empleo, Junta de Andalucía (http://www.juntadeandalucia.es/justiciaeinterior/opam/sites/default/files/DOC/texto_completo_OPIA_II.pdf).

Rinken, S. y Velasco Dujo, S. (2010): «La evolución de la opinión pública andaluza ante la inmigración: indicios de estabilidad y cambio en época de crisis económica». Migraciones, $\mathrm{n}^{\circ}$ 28: 55-86

(http://revistas.upcomillas.es/index.php/revistamigraciones/issue/ view/56) .

Schlueter, E., Meuleman, B. y Davidov, E. (2013): «Immigrant integration policies and perceived group threat: a multilevel study of 27 Western and Eastern European countries». Social Science Research 42 (3): 670-82.

Zamora-Kapoor, A. (2013): A Structural Explanation for Anti-immigrant Sentiment: Evidence from Belgium and Spain. New York: Columbia University (tesis doctoral; http://academiccommons.columbia.edu/item/ac:163309). 